\title{
TRANSIENT ANALYSIS OF A RAILGUN WITH PERMANENT MAGNETS SUPPORT
}

\author{
Andrzej WAINDOK*, Paweł PIEKIELNY* \\ "Faculty of Electrical Engineering, Automatic Control and Informatics, Department of Electrical Engineering and Mechatronics, \\ Opole University of Technology, ul. Prószkowska 76, 45-758 Opole, Poland \\ a.waindok@po.opole.pl, bp.piekielny@po.opole.pl
}

received 10 October 2016, revised 30 November 2017, accepted 4 December 2017

\begin{abstract}
The calculation and measurement results of transients for an electrodynamic accelerator with permanent magnet support have been presented in this paper. The calculations have been made using the magnetostatic model in the Maxwell software, as well as using a Matlab/Simulink transient model. The waves of mechanical parameters (projectile velocity and acceleration, force) and electric ones (excitation current and capacitor voltage) have been analyzed for different supply conditions (voltage value, capacitance). The efficiency and projectile energy have been studied as well. The mathematical models have been verified experimentally using the original laboratory stand. A good conformity between calculation and measurement results has been obtained.
\end{abstract}

Key words: Electrodynamic Accelerators with Permanent Magnets, Field-Circuit Modelling, Transient Calculation, Measurement Verification

\section{INTRODUCTION}

Electrodynamic accelerators (railguns) have become increasingly popular in recent years. There are carried out many works and researches in terms of both military (McNab and Beach, 2007; Gosiewski and Kłoskowski, 2008; Hundertmark et al., 2013) and industrial applications (Poniaev et al., 2015; Hogan et al., 2013; Domin and Kluczczyński, 2013) of the device. The railguns are an alternative for coilgun constructions (Waindok and Mazur, 2011; Piskur, 2010), mostly due to better performance (efficiency, projectile velocity). A disadvantage of such electrodynamic accelerator is the high cost of assembling and problem with rails and electric contact degradation (Cooper et al., 2007; Tang et al., 2015; Wild et al., 2014). Another problem is a very high current peak of KA to even MA appearing in some milliseconds. The efficiency of the device is low, as well.

In order to increase the efficiency of the railgun there is a need not only to perform the experimental work, but also to create a proper calculation model, which would simulate the physical object with sufficient accuracy (Kluszczyński and Domin, 2015). The proper model could be used, for example, in order to increase the thrust, without increasing the excitation current (Waindok and Piekielny, 2013; Gieras et al., 2011). One of the method is the optimization of the magnetic circuit. It requires the development of a magnetostatic model using field analysis, for example 3D finite element method (FEM). The transient model is very important as well. It enables to follow the influence of supplying parameters and initial conditions on the waves connected with discharges, which allows to improve the efficiency of the whole system.

In the paper, the calculation and measurement results for the original electrodynamic accelerator with iron core and permanent magnets have been presented. The device has been developed in the Department of Electrical Engineering and Mechatronics at Opole University of Technology. The calculations have been carried out using a field-circuit model of the device (Zimon et al., 2012). For magnetostatic analysis, the Maxwell software has been used. The parameters obtained in the field calculations have been used in the transient (circuit) model, which has been implemented in the Matlab/Simulink software.

\section{PHYSICAL MODEL}

The picture of the accelerator with ferromagnetic core and permanent magnets is presented in Fig. 1a. The magnetic field has two sources: a current flowing through the circuit and permanent magnets. The iron core has been used in order to focus the magnetic field lines in the projectile area. Therefore, in relation to the core-less accelerator, the thrust could be increased for the same excitation current value.

Before construction of a prototype, some calculations have been carried out in order to set up the dimensions of the core and permanent magnets (Fig. 1b). The following design constraints have been assumed: a cross-section of each rail less than $100 \mathrm{~mm}^{2}$, the distance between them $a=12 \mathrm{~mm}$, the length of the device $l=200 \mathrm{~mm}$. The non-linear characteristic of the core has been measured and taken into account (Fig. 2). The measurement has been performed for a ring-shaped magnetic sample (Tumanski, 2011). The sinusoidal voltage supply system has been used. The magnetic field strength in the magnetic circuit has been determined with using the Ampere's circuital law. The magnetic flux density value in the sample has been determined according to Faraday's law, using the mean value of the induced voltage.

The projectile core of $25 \mathrm{~mm}$ length (Fig. 3 ) has been made of PF CC 201 material (textolite). The PF CC 201 has been chosen due to its ease processing, low mass $(m=2.5 \mathrm{~g})$, relatively 
high stiffness and high heat resistance. The reduction of the mass allows to take the shot at smaller values of the excitation current. The active part of the projectile is made of an OFC (Oxygen-Free Copper) wire, which ensures a good electric contact between rails and the projectile. The OFC wire was selected due to high conductivity and friction resistivity, which is very important in dynamic systems with high current values. The rails have been made of brass.

a)

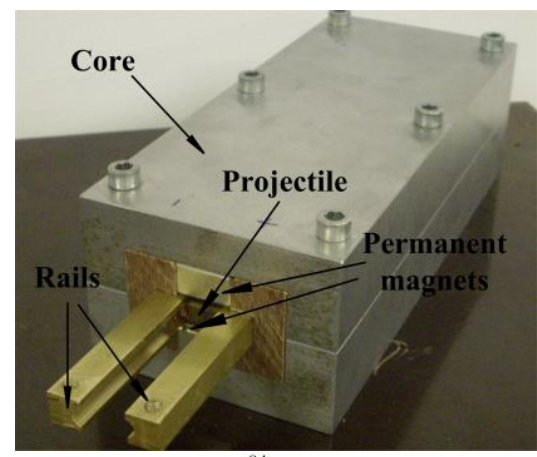

b)

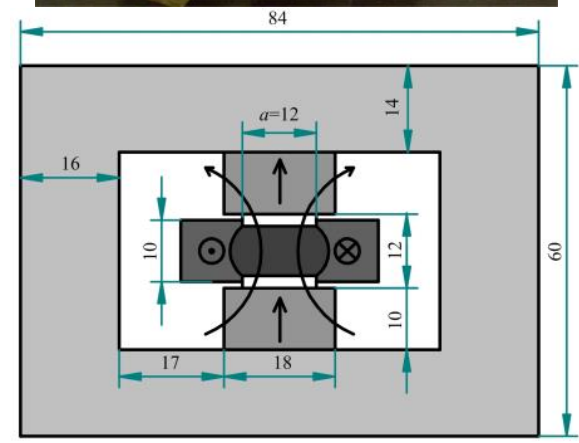

Fig. 1. Electrodynamic accelerator with ferromagnetic core and permanent magnets: a) picture of the prototype; b) cross-section (dimensions in $\mathrm{mm}$ )

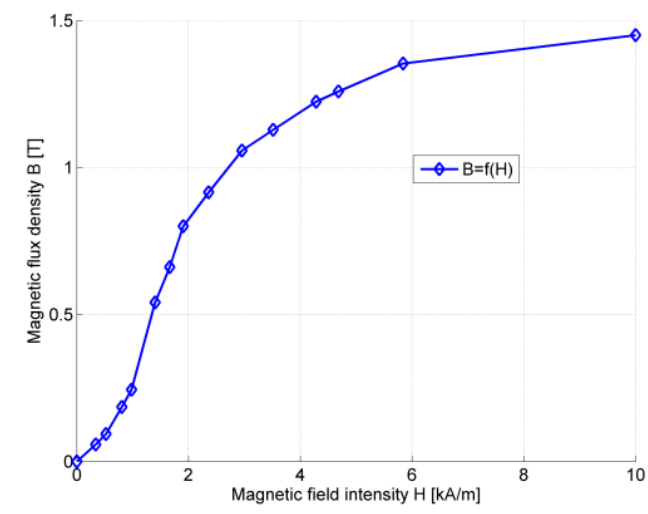

Fig. 2. Measured B/H curve of the used ferromagnetic core

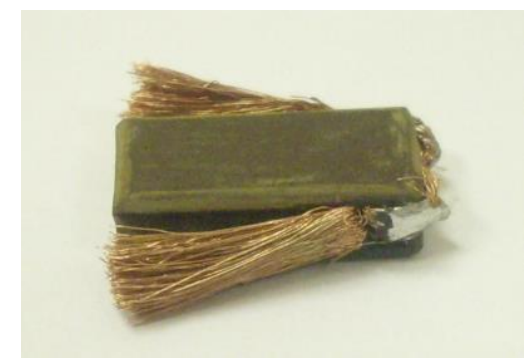

Fig. 3. Picture of the projectile

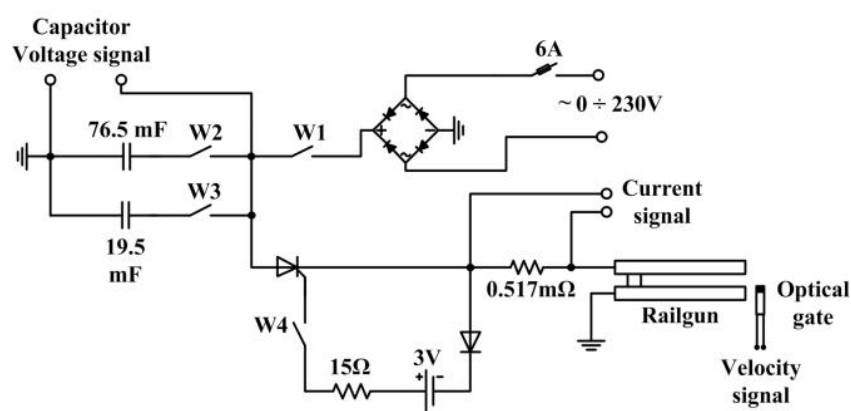

Fig. 4. Electrical circuit diagram

The electrical circuit diagram of the original laboratory stand (Piekielny, 2015) is shown in Fig. 4. It consists of two main parts: the power supply circuit and measuring system. The power source is a capacitor bank with a total capacity of $96 \mathrm{mF}$ and nominal voltage of $350 \mathrm{~V}$. To trigger the shot a high power thyristor was used (model T95-1900 from Kubara LAMINA Company). During the shot the following signals are recorded using an oscilloscope: the voltage on the capacitor bank $U$, the excitation current $I$ and the average muzzle velocity of the projectile $v$. The current measurement was made by recording the voltage drop on a 0.517 $\mathrm{mOhm}$ resistance. Velocity of the projectile was determined by measuring the flying time through the optical gate.

\section{MATHEMATICAL MODEL}

In order to determine the magnetic field integral parameters, the finite element method, implemented in the program Maxwell, has been used. The voltage boundary conditions were assumed on the rails ends (Fig. 5). On the outer boundaries the zero Dirichlet condition has been assumed. The eddy current effect has been neglected. Using this model, the integral parameters of the field have been determined. The magnetic flux on the surface $S$ (limited by the rails and projectile, Fig 6) was calculated with using the expression:

$\Phi=\int_{S} \mathrm{~B} \cdot \mathrm{n} d S$

where: $\Phi$ - magnetic flux on the surface $S, \mathbf{B}$ - magnetic flux density vector, $\mathbf{n}$ - unit vector normal to surface $S, S$ - surface limited by the rails and projectile, parallel to the plane YZ (Fig. 6).

Lorentz force $\mathbf{F}$ acting on the projectile was calculated according to equation:

$\mathbf{F}=\int_{\Omega}(\mathbf{J} \times \mathbf{B}) d \Omega$

where: $\mathbf{J}$ - current density vector in the projectile, $\Omega$ - volume of the projectile.

The dynamic inductance $L_{d}$ of the accelerator was determined by the expression:

$L_{d}=\frac{\partial \Phi}{\partial i}=\frac{1}{i} \frac{\partial W_{m}}{\partial i}$

where: $i$ - current flowing through the rails, $W_{m}$ - magnetic energy.

In order to select the proper mesh discretization, the calculations for two different meshes have been made (Fig. 5). In the first case an adaptive method for mesh generation has been used. The algorithm has created quite coarse mesh presented in Fig. 5a. In the second case, the maximum size of the mesh elements in each sub-area has been forced (Fig. 5b), which signif- 
icantly increases the number of elements (dense mesh). In table 1 , the calculation results for both types of mesh have been given. Due to small differences between obtained results (below $1.1 \%$ in case of thrust and below $0.2 \%$ for excitation current) and due to significantly shorter calculation time, the coarse mesh generated by an adaptive method, has been used. It should be mentioned, that the calculation time for magnetostatic models is a very important quantity, since the calculations of integral parameters (magnetic flux, force and inductance) are made for different positions of the projectile and different excitation current values.
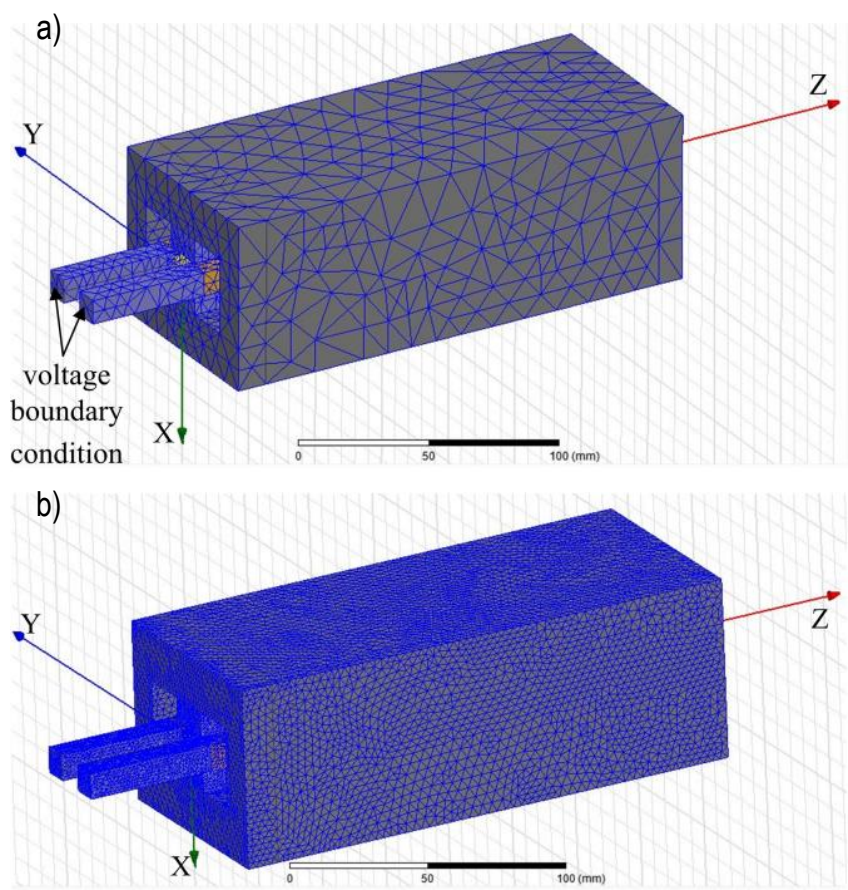

Fig. 5. Two analyzed discretization meshes: a) coarse mesh; b) dense mesh

Tab. 1. Comparison of the calculation results for two different meshes

\begin{tabular}{|c|c|c|c|c|c|}
\hline $\begin{array}{c}\text { Mesh } \\
\text { type }\end{array}$ & Voltage & $\begin{array}{c}\text { Excitation } \\
\text { current }\end{array}$ & Force & $\begin{array}{c}\text { Calc. } \\
\text { time }\end{array}$ & $\begin{array}{c}\text { Number } \\
\text { of elements }\end{array}$ \\
\hline- & $U[\mathrm{~V}]$ & $I[\mathrm{~A}]$ & $F[\mathrm{~N}]$ & $t[\mathrm{~h}: \mathrm{m}: \mathrm{s}]$ & $n$ \\
\hline Dense & 150 & 26274.13 & 543.26 & $7: 28: 09$ & 1230778 \\
\hline Coarse & 150 & 26227.46 & 537.45 & $0: 02: 48$ & 60046 \\
\hline
\end{tabular}

The analysis of accelerator operation is based not only on static, but also on the dynamic calculations. Thus, a field-circuit model have been developed for a transient analysis. The equations describing the dynamic model of the railgun have been obtained with using the Euler-Lagrange method:

$\frac{d}{d t}\left[\begin{array}{l}v \\ i\end{array}\right]=\left[\begin{array}{cc}-\frac{D}{m} & 0 \\ -\frac{\partial \Psi(i, x)}{\partial x} & -\frac{R}{L_{d}(i, x)}\end{array}\right]\left[\begin{array}{l}v \\ i\end{array}\right]+\left[\begin{array}{c}\frac{F(i, x)}{m} \\ -\frac{q}{C} \\ L_{d}(i, x)\end{array}\right]$

The first equation describes the mechanical part of the system, while the second one describes the electrical part. The above equations have been implemented in the Matlab-Simulink software. The values of force and magnetic flux vs. position and excitation current values have been calculated with using the FEM magnetostatic model and included in the form of Look-up tables.

\section{MAGNETOSTATIC CALCULATION RESULTS}

The current density and the thrust values, as well as magnetic field distribution have been determined for different values of the excitation voltage (-60 V to $200 \mathrm{~V})$. In Fig. 7a an exemplary distribution of the current density (for $U=150 \mathrm{~V}$ ) has been shown (the projectile is placed in position $z_{i}=3 \mathrm{~cm}$ (Fig.6).

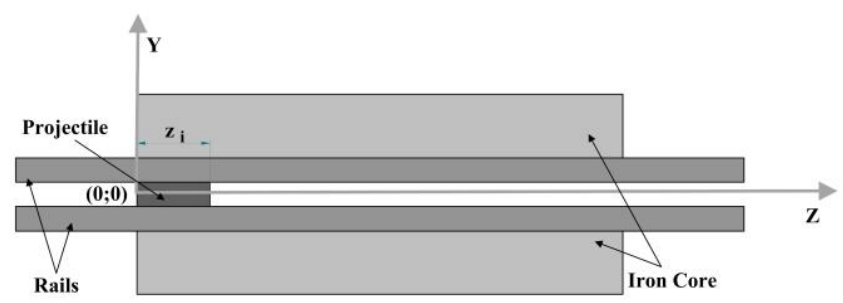

Fig. 6. Initial position of the projectile

The highest value of the current density is observed in the area of the projectile, on the inner edges of the conductive part (more than $3 \mathrm{kA} / \mathrm{mm}^{2}$ ). In Fig. $7 \mathrm{~b}$ the magnetic flux density distribution for $U=150 \mathrm{~V}$ has been depicted. Accordingly to the current density distribution, the highest value of the magnetic flux density is observed in the projectile area (about 4.13 T). Such a high value is due to high current density value. In the iron parts of the railgun, the magnetic density value is much lower (below $2 \mathrm{~T}$ ).

a)

b)

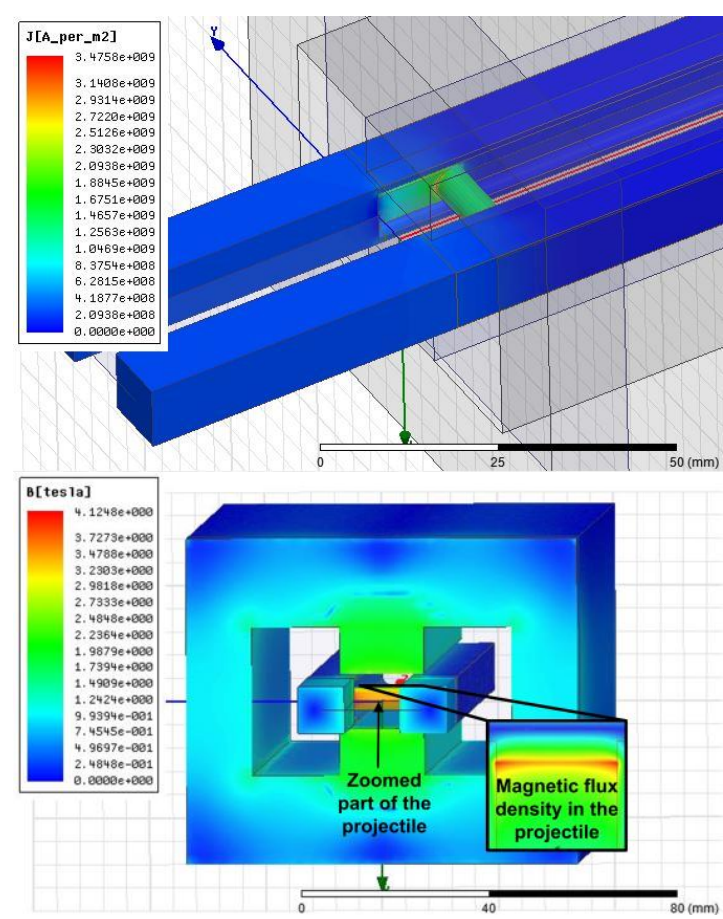

Fig. 7. Calculation results for $U=150 \mathrm{~V}$ : a) current density distribution in the rails and projectile; b) magnetic flux density distribution

The calculation results for electrodynamic force and magnetic flux vs. excitation current value $I$ and projectile position $z$ are presented in Fig. 8. The force value is almost insensitive vs. projectile position and changes exponentially vs. excitation current value. The magnetic flux changes linearly both vs. I and $z$. According to equation (4), in calculation of transients the dynamic 
inductance $L_{d}$ is an important parameter. The graph of the $L_{d}=f(z, i)$ has been presented in Fig. 9 . Its value weakly depends on the excitation current and is linearly dependent on the projectile position coordinate.

a)

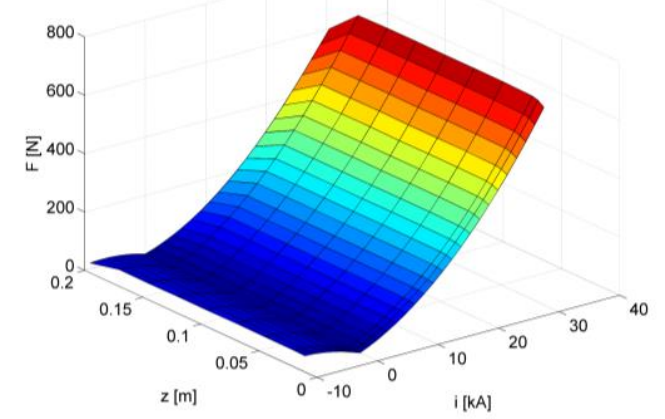

b)

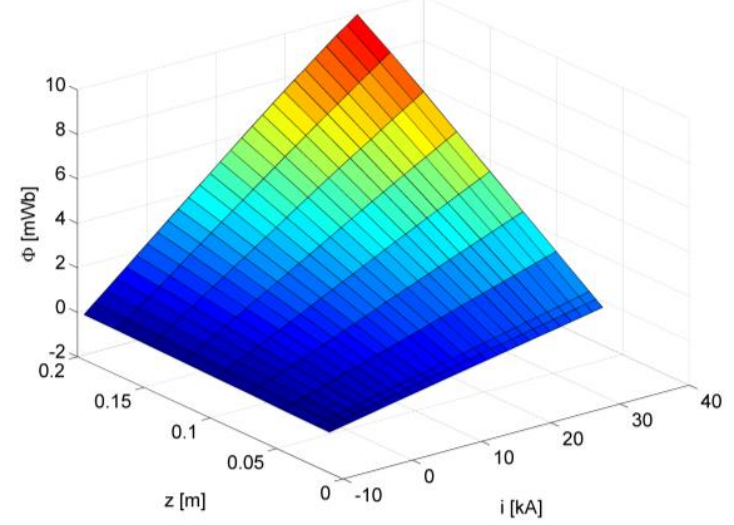

Fig. 8. Integral parameters vs. projectile position and excitation current value: a) electrodynamic force; b) magnetic flux

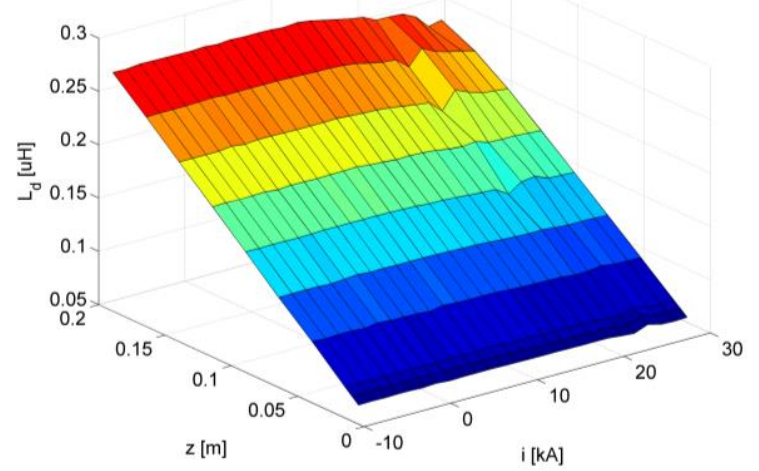

Fig. 9. Dynamic inductance vs. current value and projectile position

\section{TRANSIENT CALCULATION AND MEASUREMENT RESULTS}

The measurements for different capacitors and voltage values have been made. Some results are presented in Fig. 10. Increasing of the capacitance values raises the discharge time and slightly increases the peak current value (Fig. 10a). The capacitor voltage level affects only the current value - increasing of the voltage increases the current in approximately a linear way (Fig. 10b).

a)

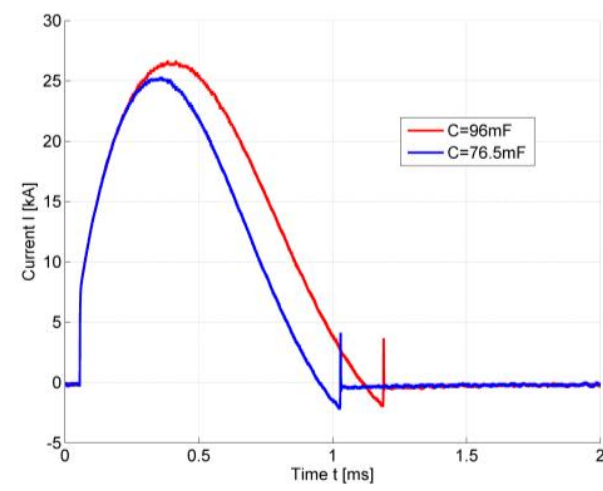

b)

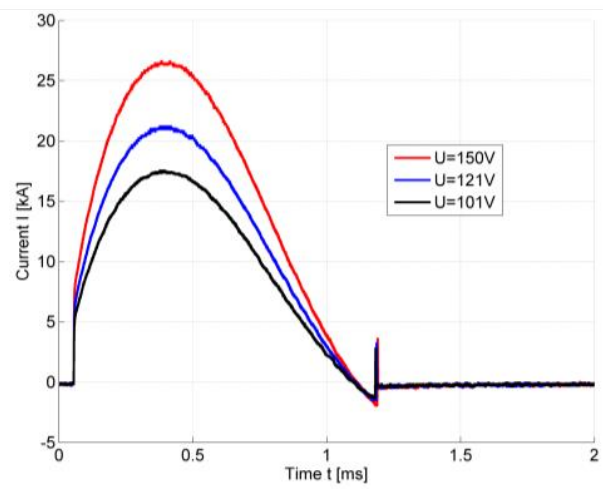

Fig. 10. Current excitation waves for different supply parameters:

a) constant voltage value $(\mathrm{U}=150 \mathrm{~V})$ - different capacity values;

b) constant capacitance value $(\mathrm{C}=96 \mathrm{mF})$ - variable voltage values

Using the original laboratory stand, a measurement verification of the selected calculation results have been carried out. The resistance and inductance of supply cables were assumed to be equal $R=2.75 \mathrm{mOhm}$ and $L=0.98 \mu \mathrm{H}$, respectively. Due to the motion of the projectile additional parameters have to be included i.e. mass of the projectile $m=4.51 \mathrm{~g}$, coefficient of the kinetic friction $D=0.2 \mathrm{Ns} / \mathrm{m}$ and the value of the air resistance coefficient $C_{x}=1.05$

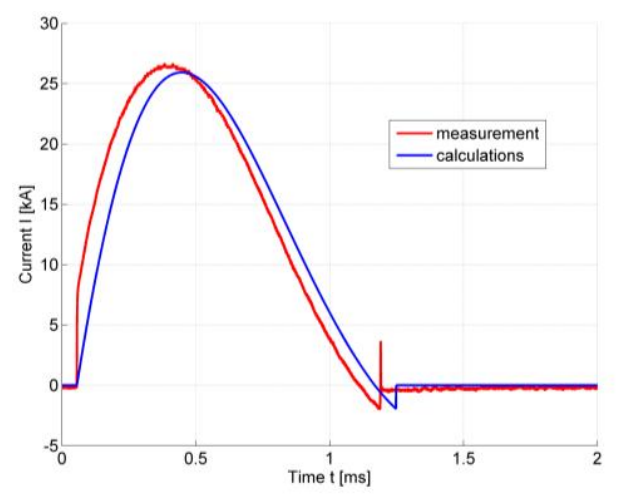

Fig. 11. Calculation and measurement results of the current waveform for $\mathrm{U}=150 \mathrm{~V}$ and $\mathrm{C}=96 \mathrm{mF}$

In Fig. 11, results of calculated and measured current waveforms for $U=150 \mathrm{~V}$ and $C=96 \mathrm{mF}$ are presented. The current peak visible in the measurement results is due to commutation 
of the thyristor, which switches off the inductive circuit under nonzero conditions and generates a voltage disturbance in the circuit. The current is measured based on the voltage drop on the resistor. Thus the voltage disturbance is visible in measured waves.

There are also visible differences between measured and calculated shape of current waves (Fig. 11). Therefore, some modifications have been proposed in the mathematical model. From the experimental research came out, that in the system some time lags are existing between the thyristor triggering time and the response time of the circuit rails-projectile. The system behaves in some ways like a transmission line. Therefore, in the mathematical model, a fixed time delay block for the inductance value has been added. The delay time has been chosen based on the experimental tests as $\Delta t=4.4 \mu \mathrm{s}$. After the delay time, the static inductance value of the accelerator circuit raises from 0 to 0.98 $\mu \mathrm{H}$. The results for the modified field-circuit model have been presented in Fig. 12a. In the case of current wave, a very good conformity between calculation and measurement results is observed. The measured voltage wave on the capacitors differs slightly from the calculated one (Fig. 12b). However, the mathematical model is sufficiently precise and could be used in future calculations. The negative value of the capacitor voltage is caused by the finite switching-off time of the thyristor (about $100 \mu \mathrm{s}$ ).

The measurement verification of the projectile velocity has been made, as well (Tab. 2). The differences between calculated and measured results do not exceed $10 \%$ and are observed for the lowest velocity values. In the case of the highest observed velocities, the difference does not exceed $1.1 \%$. a)

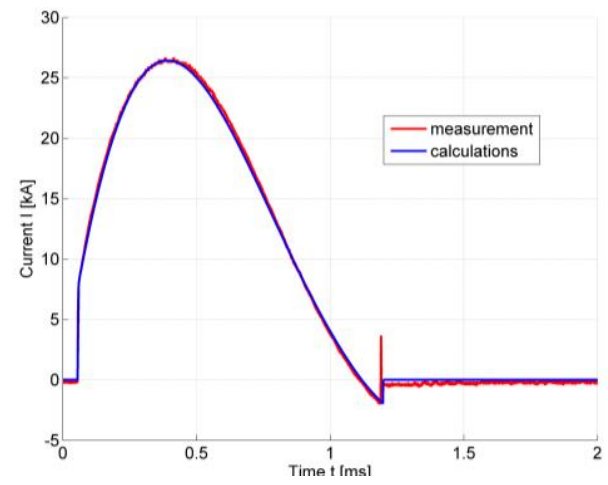

b)

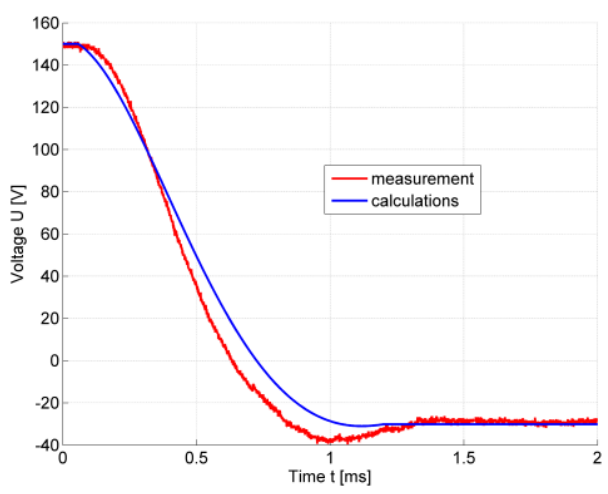

Fig. 12. Measurement verification of the modified field-circuit model for $\mathrm{U}=150 \mathrm{~V}$ and $\mathrm{C}=96 \mathrm{mF}$ : a) excitation current vs. time; b) voltage waves

Tab. 2. The dynamic parameters for different power supply configurations

\begin{tabular}{|c|c|c|c|c|c|c|}
\hline Voltage & Capacity & Calculated current peak & Measured current peak & Calculated velocity & Measured velocity & Force \\
\hline$U[\mathrm{~V}]$ & $C[\mathrm{mF}]$ & $I_{\max }[\mathrm{A}]$ & $I_{\max }[\mathrm{A}]$ & $v[\mathrm{~m} / \mathrm{s}]$ & $v[\mathrm{~m} / \mathrm{s}]$ & $F_{\max }[\mathrm{N}]$ \\
\hline 150 & 96.0 & 26422 & 26692.5 & 61.35 & 60.98 & 549.74 \\
\hline 150 & 76.5 & 24868 & 25145.1 & 47.86 & 47.71 & 501.30 \\
\hline 121 & 96.0 & 21303 & 21276.6 & 42.23 & 44.64 & 395.18 \\
\hline 121 & 76.5 & 20045 & 20116.1 & 32.57 & 34.53 & 361.22 \\
\hline 101 & 96.0 & 17767 & 17620.9 & 30.62 & 33.78 & 302.03 \\
\hline 101 & 76.5 & 16715 & 16769.8 & 23.29 & 25.83 & 276.39 \\
\hline
\end{tabular}

a)

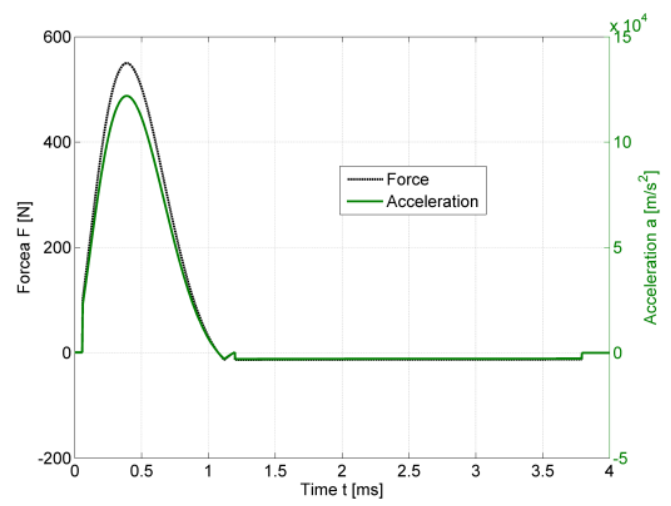

b)

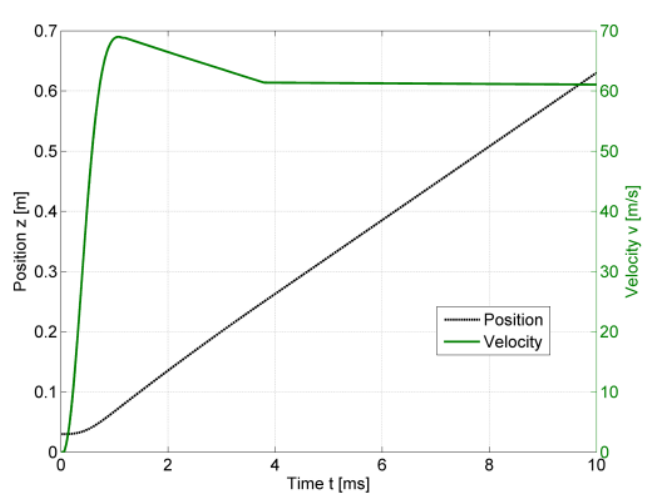

Fig. 13. Calculated waves $(\mathrm{U}=150 \mathrm{~V}, \mathrm{C}=96 \mathrm{mF})$ : a) force and acceleration; b) position and velocity

Using the field-circuit model, some additional calculations have been carried out. They concern quantities, which are very difficult to measure, i.e. thrust, acceleration, velocity and position of the projectile. The initial position of the projectile equal to $z_{i}=3$ $\mathrm{cm}$ has been included in the model. In Fig. 13 some results are presented. The shape of force and acceleration waves is the same (Fig. 13a). The maximum value of the acceleration reaches very high value $\left(121890 \mathrm{~m} / \mathrm{s}^{2}\right)$, which is due to small mass of the 
movable element and due to relatively high force (peak value of $549.74 \mathrm{~N}$ ). Waveforms of the position and velocity (Fig. 13b) indicate, that the duration of force and current impulses (about $1 \mathrm{~ms}$ ) is much shorter than the duration of the projectile movement in rails (about $4 \mathrm{~ms}$ ). It means, that the capacitance could be increased in order to exploit the full potential of the presented accelerator.

\section{CONCLUSIONS}

A study of the mathematical and physical models of the electrodynamic accelerator (railgun) with permanent magnets support has been presented in the paper. The obtained results allow to formulate some conclusions:

- the capacitance value has an impact mainly on the duration of current pulse. Increasing the capacity influences only slightly the peak value of the excitation current (Fig. 10a).;

- the initial capacitor voltage value affects mainly the excitation current value (Fig. 10b).;

- mathematical models which do not take into account the additional time delay in the system do not simulate the physical object with a sufficient precision (Fig. 11).;

- for the correct calculation of the projectile velocity, an appropriate choice of the friction coefficient value is important.

The efficiency of the railgun has been determined as well. The measurement results have been presented in Tab. 3 . In our tests the efficiency value did not exceed $1 \%$ and increases along with the energy value. The future works will be focused on increasing this parameter.

Tab. 3. Measured efficiency of the investigated accelerator

\begin{tabular}{|c|c|c|c|c|}
\hline Voltage & Capacity & $\begin{array}{c}\text { Energy } \\
\text { stored in the } \\
\text { capacitors }\end{array}$ & $\begin{array}{c}\text { Kinetic } \\
\text { energy of } \\
\text { projectile }\end{array}$ & Efficiency \\
\hline$U[\mathrm{~V}]$ & $C[\mathrm{mF}]$ & $E[\mathrm{~J}]$ & $E[\mathrm{~J}]$ & $\eta[\%]$ \\
\hline 150 & 96.0 & 1068.75 & 8.39 & 0.78 \\
\hline 150 & 76.5 & 843.75 & 5.13 & 0.61 \\
\hline 121 & 96.0 & 695.45 & 4.49 & 0.65 \\
\hline 121 & 76.5 & 549.04 & 2.69 & 0.49 \\
\hline 101 & 96.0 & 484.55 & 2.57 & 0.53 \\
\hline 101 & 76.5 & 382.54 & 1.50 & 0.39 \\
\hline
\end{tabular}

The level of complexity of the phenomena occurring in the electrodynamic accelerator is relatively high. Thus, some further investigations for improving both physical and computational models are planned. In particular, the development of the experimental stand will be carried out.

\section{REFERENCES}

1. Cooper K.P., Jones H.N., Meger R.A. (2007), Analysis of railgun barrel material, IEEE Transactions on Magnetics, 43(1), 120-125.

2. Domin J., Kluszczynski K. (2013), Hybrid pneumatic-electromagnetic launcher - general concept, mathematical model and results of simulation, Przegląd Elektrotechniczny, 89(12), 21-25.

3. Gieras J. F., Piech Z. J., Tomczuk B. (2011), Linear synchronous motors, CRC Press, Taylor \& Francis Group.

4. Gosiewski Z., Klosowski P. (2008), Support of work of electromagnetic gun by using permanent magnets, Bulletin of the Military University of Technology, 57(3), 87-95.

5. Hogan J.D., Spray J.G., Rogers R.J., Vincent G., Schneider M., (2013), Dynamic fragmentation of planetary materials: ejecta length quantification and semi-analytical modelling, International Journal of Impact Enginee-ring, 62, 219-228.

6. Hundertmark S., Schneider M., Simicic D., Vincent G., (2013), Experiments to increase the used energy with the PEGASUS railgun installation, http://arxiv.org/pdf/1402.6094v1.pdf.

7. Kluszczynski K., Domin J. (2015), Two module electromagnetic launcher with pneumatic assist: modelling, computer simulations and laboratory investigations, COMPEL (The International Journal for Computation and Mathematics in Electrical and Electronic Engineering), 34(3), 691-709.

8. McNab I.R., Beach F.C. (2007), Naval railguns, IEEE Transactions on Magnetics, 43(1), 463-468.

9. Piekielny P. (2015), The measurement stand for the testing of the electrodynamic accelerator parameters, Zeszyty Naukowe Politechniki Opolskiej, 71, 53-54.

10. Piskur P. (2010), Multiparameter optimization of construction and control of an electromagnetic launcher for application in linear drive of machining tool, Ph.D. theses, Koszalin University of Technology, Department of Mechatronics, Nanotechnology and Vacuum Technology, Koszalin, Poland. (in polish)

11. Poniaev S.A., Bobashev S.V., Zhukov R.O., Sedov A.I., Izotov S.N., Kulakov S.L., Smirnova M.N., (2015), Small-size railgun of $\mathrm{mm}$-size solid bodies for hypervelocity material testing, Acta Astronautica, 109, 162-165.

12. Tang L., He J., Chen L., Xia S., Feng D., Li J., Yan P., (2015), Study of some influencing factors of armature current distribution at current ramp-up stage in railgun, IEEE Transactions on Plasma Science, 43(5), 1585-1591.

13. Tumanski S. (2011), Handbook of Magnetic Measurements, CRC Press.

14. Waindok A., Mazur G. (2011), Mutual inductances in a mathematical model of the three-stage reluctance accelerator, 3rd International Students Conference on Electrodynamics and Mechatronics (SCE III), Opole, Poland, 115-118.

15. Waindok A., Piekielny P. (2013), Analysis of selected constructions of the electrodynamic accelerator, International Symposium on Electrodynamic and Mechatronic Systems (SELM), Zawiercie, Poland, 51-52.

16. Wild B., Schuppler C., Alouahabi F., Schneider M., Hoffman R. (2014), The influence of the rail material on the multishot performance of the Rapid Fire Railgun (RAFIRA), 17th International Symposium on Electromagnetic Launch Technology (EML), La Jolla, CA, USA.

17. Zimon J., Tomczuk B., Wajnert D. (2012), Field-circuit modeling of AMB system for various speeds of the rotor, Journal of Vibroengineering, 14(1), 165-170. 